Chapman University

Chapman University Digital Commons

Mathematics, Physics, and Computer Science

Faculty Articles and Research

Science and Technology Faculty Articles and

Research

7-15-2015

\title{
On the Relationship Between the North Atlantic Oscillation and Early Warm Season Temperatures in the Southwestern United States
}

\author{
Boksoon Myoung \\ Chapman University, bmyoung@chapman.edu \\ Seung Hee Kim \\ Chapman University, sekim@chapman.edu \\ Jinwon Kim \\ University of California - Los Angeles \\ Menas Kafatos \\ Chapman University, kafatos@chapman.edu
}

Follow this and additional works at: https://digitalcommons.chapman.edu/scs_articles

Part of the Atmospheric Sciences Commons, and the Environmental Monitoring Commons

\section{Recommended Citation}

Myoung, B., Kim, S.H., Kim, J., Kafatos, M.C., 2015. On the relationship between the North Atlantic Oscillation and early warm season temperatures in the southwestern US. J. Climate 28.14: 5683-5698. doi:10.1175/JCLI-D-14-00521.1

This Article is brought to you for free and open access by the Science and Technology Faculty Articles and Research at Chapman University Digital Commons. It has been accepted for inclusion in Mathematics, Physics, and Computer Science Faculty Articles and Research by an authorized administrator of Chapman University Digital Commons. For more information, please contact laughtin@chapman.edu. 


\section{On the Relationship Between the North Atlantic Oscillation and Early Warm Season Temperatures in the Southwestern United States}

\section{Comments}

This article was originally published in Journal of Climate, volume 28 , issue 14 , in 2015 . DOI: 10.1175/

JCLI-D-14-00521.1

\section{Copyright}

(c) Copyright 2015 American Meteorological Society (AMS). Permission to use figures, tables, and brief excerpts from this work in scientific and educational works is hereby granted provided that the source is acknowledged. Any use of material in this work that is determined to be "fair use" under Section 107 of the U.S. Copyright Act September 2010 Page 2 or that satisfies the conditions specified in Section 108 of the U.S. Copyright Act (17 USC §108, as revised by P.L. 94-553) does not require the AMS's permission. Republication, systematic reproduction, posting in electronic form, such as on a web site or in a searchable database, or other uses of this material, except as exempted by the above statement, requires written permission or a license from the AMS. Additional details are provided in the AMS Copyright Policy, available on the AMS Web site located at (http://www.ametsoc.org/) or from the AMS at 617-227-2425 or copyrights@ametsoc.org. 


\title{
¿On the Relationship between the North Atlantic Oscillation and Early Warm Season Temperatures in the Southwestern United States
}

\author{
BoKsoOn Myoung AND Seung HeE KIM \\ Center of Excellence in Earth Systems Modeling and Observations, Chapman University, Orange, California \\ JINWON KIM \\ Joint Institute for Regional Earth System Science and Engineering, University of California, Los Angeles, \\ Los Angeles, California \\ MENAS C. KAFATOS \\ Center of Excellence in Earth Systems Modeling and Observations, Chapman University, Orange, California
}

(Manuscript received 24 July 2014, in final form 7 April 2015)

\begin{abstract}
It is reported herein that the North Atlantic Oscillation (NAO), which has been known to directly affect winter weather conditions in western Europe and the eastern United States, is also linked to surface air temperature over the broad southwestern U.S. (SWUS) region, encompassing California, Nevada, Arizona, New Mexico, Utah, and Colorado, in the early warm season. The authors have performed monthly time-scale correlations and composite analyses using three different multidecadal temperature datasets. Results from these analyses reveal that NAO-related upstream circulation positively affects not only the means, but also the extremes, of the daily maximum and minimum temperatures in the SWUS. This NAO effect is primarily linked with the positioning of upper-tropospheric anticyclones over the western United States that are associated with development of the positive NAO phase through changes in lower-tropospheric wind directions as well as suppression of precipitation and enhanced shortwave radiation at the surface. The effect is observed in the SWUS only during the March-June period because the monthly migration of anticyclones over the western United States follows the migration of the NAO center over the subtropical Atlantic Ocean. The link between the SWUS temperatures and NAO has been strengthened in the last 30-yr period (1980-2009), compared to the previous 30-yr period (1950-79). In contrast to the NAO-SWUS temperature relationship, El Niño-Southern Oscillation (ENSO) and the Pacific decadal oscillation (PDO) show only marginal correlation strengths in several limited regions for the same 60 -yr period.
\end{abstract}

\section{Introduction}

It has been well established that interannual atmospheric and oceanic variabilities strongly affect regional weather by modulating the atmospheric circulations and, by extension, precipitation and surface air temperatures through atmospheric teleconnections (Shukla

๑ Denotes Open Access content.

Corresponding author address: Seung Hee Kim, Center of Excellence in Earth Systems Modeling and Observations, Chapman University, 1 University Drive, Orange, CA 92866.

E-mail: sekim@chapman.edu and Wallace 1983; McCabe and Dettinger 1999). The linkages between multiple climate indices [e.g., El NiñoSouthern Oscillation (ENSO), Pacific decadal oscillation (PDO), North Atlantic Oscillation (NAO), Atlantic multidecadal oscillation (AMO), and Arctic Oscillation (AO)] and weather conditions in the United States have been extensively investigated and documented in a number of studies (e.g., Hurrell and van Loon 1997; Gershunov and Barnett 1998; Wanner et al. 2001; McCabe et al. 2004; Sutton and Hodson 2005; Ault et al. 2011; Loikith and Broccoli 2012).

ENSO and NAO/AO are among the most important indices for measuring climate variability. In the southwestern United States (SWUS), El Niño years introduce anomalously wet and cold winters as a result of enhanced 
subtropical jets (Ropelewski and Halpert 1987; Gershunov and Barnett 1998; McCabe and Dettinger 1999; Myoung and Deng 2009). On the other hand, the southeastern U.S. region is more likely to experience above-normal winter temperatures accompanied by below-normal snowfall in positive NAO years (Hurrell and van Loon 1997; Kapala et al. 1998; Higgins et al. 2000). Recently, reduced precipitation patterns and associated drought conditions in winter and early spring over the western United States (WUS) have been suggested to be linked with AO variability (McAfee and Russell 2008; Wang et al. 2014). The changes in NAO phase and intensity are also responsible for interannual variability and long-term trends of wintertime temperatures and rainfall extremes in the southeastern United States, the northeastern United States, and western Europe (Wettstein and Mearns 2002; Brown et al. 2008; Scaife et al. 2008).

Some of the weather phenomena have been linked to multidecadal oscillations of sea surface temperature (SST) in the Pacific and the Atlantic Oceans (Dettinger et al. 1998; Enfield et al. 2001; Knight et al. 2006). For example, the PDO tends to substantially modulate the strength of the ENSO teleconnections in the WUS (e.g., intensification of the positive link between ENSO and winter precipitation in the SWUS under a positive PDO phase) (Gershunov and Barnett 1998; McCabe and Dettinger 1999; Brown and Comrie 2004). Several studies have also emphasized the role of the AMO in the intensification of Atlantic hurricanes and summer precipitation in the United States (Goldenberg et al. 2001; Curtis 2008). McCabe et al. (2004) asserted that phase combinations of the PDO and AMO are known to be critical to the occurrence of multidecadal droughts in the continental United States.

The impacts of SST variability are generally weak during the summer, although the link between summer rainfall variability [e.g., the North American monsoon (NAM) and the southeastern U.S. precipitation] and ENSO has been reported in earlier studies (Mo and Schemm 2008; Wang et al. 2010). This is primarily because the effects of local land-atmosphere interactions dominate remote SST effects (Myoung and NielsenGammon 2010; Loikith and Broccoli 2012, 2014). In the spring and fall, some of the climate variabilities may have nonnegligible effects on U.S. weather and weatherrelated phenomena (e.g., Ault et al. 2011).

NAO is an internal variability of the atmosphere, and has dominant periods ranging from a few weeks to a few years. As described above, a number of previous studies have investigated the relationships between various climate indices (NAO, etc.) and temperature variability in North America, including the United States (Hurrell and van Loon 1997; Kapala et al. 1998; Higgins et al.
2000; Wettstein and Mearns 2002; Brown et al. 2008; Wang et al. 2014). However, the connection between the NAO and the weather in the SWUS has received little attention (McAfee and Russell 2008) because the seasonal time scales that many previous studies have employed were too long to capture possible connections between the NAO and temperatures in the SWUS, which occur on shorter time scales (e.g., monthly). If the connection migrates in conjunction with the migration of the NAO center monthly, it may be obscured by averaging over a season. Additionally, the NAO teleconnection patterns may vary with climate regimes. For example, the climate shift in the late 1970s is known to have considerably changed Northern Hemispheric atmospheric circulations and teleconnection patterns (Trenberth 1990; Trenberth and Hurrell 1994).

The present study examines the relationship between mean and extreme daily temperatures in the SWUS and various climate modes, including the NAO, AMO, ENSO, and PDO. The focus is not only on the relationship between the climate modes and temperatures, but also on the spatial and temporal changes of the relationship. Temperature variability over the SWUS in the early warm season (i.e., spring and early summer) is critical for snowmelt onset and water resource management (Mote et al. 2005; Stewart et al. 2005). The growth and productivity of crops is also significantly affected by temperature variability in this period, because spring weather conditions affect planting and early phase crop development (Larcher 1995; Porter and Semenov 2005). We also explore the mechanisms underlying these connections by analyzing atmospheric circulation during the positive or negative phases of the corresponding climate modes.

\section{Data and methods}

The monthly mean NAO (Hurrell 1995; Jones et al. 1997), ENSO (Trenberth 1997), Southern Oscillation index (SOI) (Ropelewski and Jones 1987), PDO (Zhang et al. 1997; Mantua et al. 1997), AMO (Enfield et al. 2001), Pacific-North American (PNA) (Barnston and Livezey 1987), and AO (Thompson and Wallace 1998) indices used to examine climate variability are obtained from the National Oceanic and Atmospheric Administration Climate Prediction Center archives (http:// www.esrl.noaa.gov/psd/data/climateindices/list/). The ENSO index is based on the Niño-3.4 SSTs. For the temperature field [2-m daily mean daily temperature $\left(T_{\text {ave }}\right)$ ], we use the three different monthly datasets of the National Centers for Environmental PredictionNational Center for Atmospheric Research (NCEPNCAR) reanalysis $(\mathrm{R} 1)\left(2.5^{\circ} \times 2.5^{\circ}\right)(\mathrm{http}: / /$ www.esrl. 
noaa.gov/psd/data/gridded/data.ncep.reanalysis.html) (Kalnay et al. 1996), the Climatic Research Unit $(\mathrm{CRU})\left(0.5^{\circ} \times 0.5^{\circ}\right)(\mathrm{http}: / / \mathrm{www} . c r u . u e a . a c . u k /$ data $)$ (Mitchell and Jones 2005), and the North American Regional Reanalysis (NARR) (32 km) (http://www.esrl. noaa.gov/psd/data/gridded/data.narr.html) (Mesinger et al. 2006). Among these three datasets, CRU provides 2-m monthly mean daily maximum $\left(T_{\max }\right)$ and minimum $\left(T_{\min }\right)$ air temperatures. In NARR, 3-hourly temperatures are available, so daily time series of $T_{\max }$ and $T_{\min }$ can be determined using daily maximum and minimum temperatures, respectively. The atmospheric variables, 500-hPa geopotential heights, $850-\mathrm{hPa}$ winds, vertical wind velocity, cloud cover, and net shortwave radiation flux at the surface are obtained from R1. The analysis domain covers the entire United States, with special emphasis on the SWUS region, which includes California, Nevada, Arizona, New Mexico, Utah, and Colorado. The analysis covers the 60 -yr period from 1950 to 2009, except for the NARR data, which are available only for the 30-yr period from 1980 to 2009.

Our methodology of analysis is based on the linear correlation coefficients between the monthly mean values of these climate indices and the three temperature fields in the 60-yr period after removing the longterm linear trends from all indices and variables. To investigate whether these relationships have been changed by the climate shift in the late 1970s (Trenberth 1990; Trenberth and Hurrell 1994), we also examine differences of relationships between the earlier and later 30-yr periods (1950-79 and 1980-2009, respectively). Statistical significances of the differences are calculated using a bootstrap resampling technique, following Gershunov and Barnett (1998). Random selections of $30 \mathrm{yr}$ out of the $60 \mathrm{yr}$ and the remaining $30 \mathrm{yr}$ are repeated 1000 times.

Composite analyses of extreme positive and negative years of a climate index in the 60 -yr period are performed for various atmospheric variables (e.g., geopotential height at $500 \mathrm{hPa}$ and winds at $850 \mathrm{hPa}$ ) in order to find the atmospheric circulation responsible for the relationships between temperature and climate indices. A statistical significance test for the composite analysis is also performed by the bootstrap resampling technique by repeating 1000-time random selections without replacement.

\section{Results}

\section{a. NAO and temperature relationships}

The 60-yr (1950-2009) Pearson correlations between NAO and $T_{\text {ave }}$ from R1 and CRU are shown in Fig. 1 and Fig. 2, respectively. Because of negligible autocorrelations of temperature and NAO in each month, samples are assumed to be collected independently. Positive correlations (i.e., higher surface temperatures in positive NAO years) are prevalent in the eastern United States and south-central United States in January and February (not shown), as noted in previous studies (Hurrell and van Loon 1997; Kapala et al. 1998; Higgins et al. 2000). In March, the regions of the positive correlation, significant at the $95 \%$ confidence level, cover most of the continental United States, including the SWUS [Fig. 1a(i)]. They appear over the WUS and northeastern United States in April [Fig. 1a(ii)], but in May, they are limited to most of the SWUS (e.g., California, Arizona, Nevada, and Utah) and north-central United States (e.g., Wyoming, North Dakota, South Dakota, and Nebraska) [Fig. 1a(iii)]. In June, the relationship in the SWUS becomes weak, but it intensifies in the north-central U.S. region (e.g., Wyoming, North Dakota, South Dakota, and Nebraska) [Fig. 1a(iv)], indicating that the relationship shifts northward. The northward shift continues in July (not shown), demonstrating the regions of strong correlation moving into the northern part of the WUS (e.g., Washington, Oregon, Idaho, and western Montana) in July. The NAO-temperature link becomes weak in August and completely disappears from the WUS region after September until February (not shown).

The results in Fig. 1a indicate that the interannual temperature variability in the SWUS during MarchJune (denoted herein as the early warm season) is somehow linked to NAO variability, with month-tomonth spatial variations. Similar correlation patterns are also observed in the higher-resolution CRU data in Fig. 2a: a slight difference is found in May, with a broader area of significant correlation from the SWUS to the central United States in CRU [Fig. 2a(iii)], compared to R1 [Fig. 1a(iii)]. We also found significant links between NAO and monthly averages of daily temperature extremes. The correlation results of the CRU $T_{\max }$ and $T_{\min }$ monthly datasets (i.e., NAO- $T_{\max }$ vs NAO$T_{\min }$ correlations) show that NAO is positively correlated with both $T_{\max }$ and $T_{\min }$ over the same regions in Fig. 2a, but the magnitude with $T_{\min }$ is generally smaller than that with $T_{\max }$, especially over the northern regions (not shown).

Month-to-month variations of the interannual NAO $-T_{\text {ave }}$ relationship seem to coincide with those of the NAO center in the North Atlantic. According to Portis et al. (2001), the center of the subtropical high in the Atlantic migrates northwest month to month from winter to summer; such a monthly variation is difficult 
(a) 1950-2009 (60-year)

(i) MAR

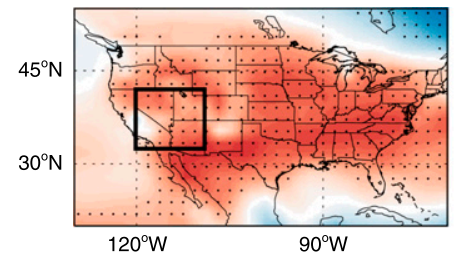

(ii) APR

(iii) MAY

(iv) JUN
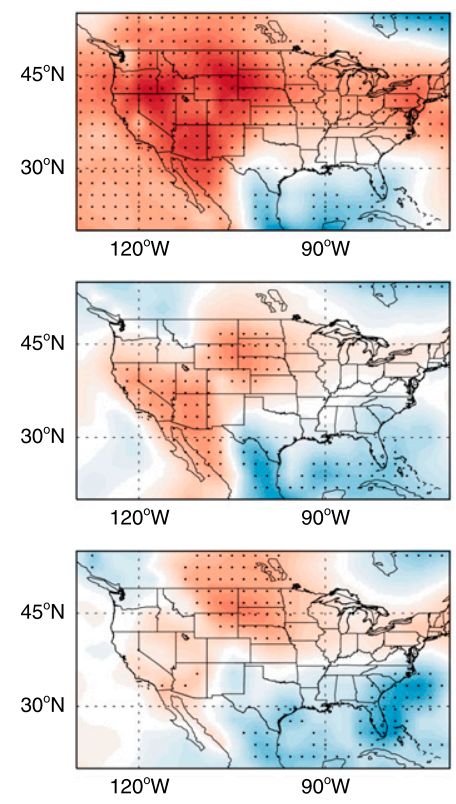

(b) 1950-1979 (30-year)
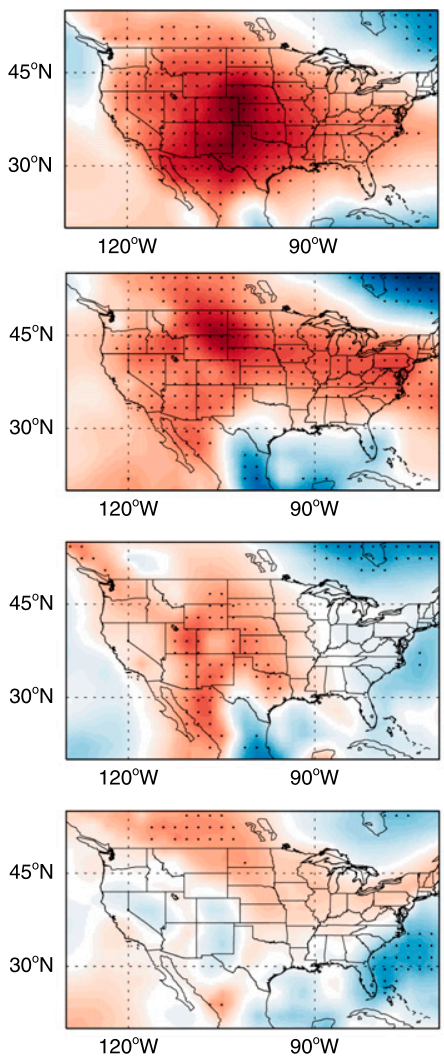

(c) $1980-2009$ (30-year)
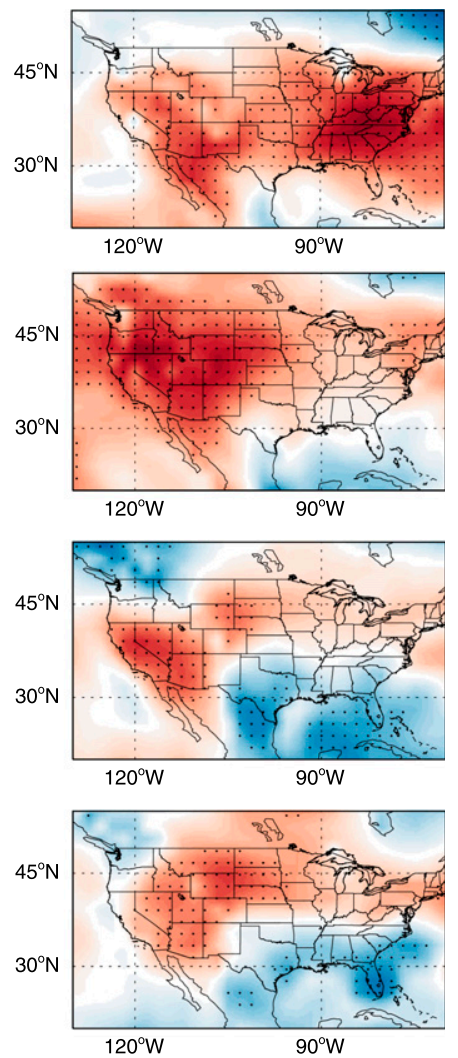

$-0.75$

0.75

FIG. 1. Pearson correlations between the NAO index and the monthly mean of $T_{\text {ave }}$ (both detrended) of the R1 dataset for (a) $60 \mathrm{yr}$ (1950-2009), (b) the first $30 \mathrm{yr}$ (1950-79), and (c) the second $30 \mathrm{yr}$ (1980-2009) from March to June. Significant correlation regions at the $95 \%$ confidence level are indicated by dots. The rectangular box shown in [a(i)] represents the central SWUS region, where the significant correlations were continuously observed during the early warm season.

to capture using seasonal-mean data. More specifically, in their study, a westward movement was dominant from January to March, while a northward movement was dominant from March to July. Although our study does not fully describe the monthly variations in the NAO- $T_{\text {ave }}$ correlations in the winter and summer, we found that the regions of significantly positive correlation move from the eastern United States to the WUS from winter to spring, presumably in conjunction with the westward movement of the NAO center. Furthermore, the NAO- $T_{\text {ave }}$ correlation shows northward movements, especially from May to July, as stated above. The geographical movements of the NAO center have been reported by Portis et al. (2001), and a similar migration pattern of the NAO- $T_{\text {ave }}$ links over the continental United States was observed in the present study. These features indicate that the statistically significant NAO-temperature relationship in the SWUS in the early warm season can be attributed to migration of the NAO-related atmospheric characteristics over the upstream regions of the Atlantic.

Interestingly, the NAO-temperature relationship has strengthened in recent decades. In Figs. 1 and 2, the second and third columns (Figs 1b, 2b and Figs. 1c, 2c, respectively) display the 30 -yr correlations for the pre1979 period (1950-79) and the post-1979 period (19802009), respectively. Differences of correlation and their significance are depicted in Fig. 3. Comparisons of the two correlation fields reveal two critical points. First, the NAO- $T_{\text {ave }}$ relationships over the SWUS were strengthened in the post-1979 period, especially in April, May, and June. Particularly in June, the magnitude of the correlation over the SWUS increased dramatically, which is statistically significant at the $95 \%$ confidence level. Second, there is a tendency that the correlations in the SWUS were strengthened in the recent $30 \mathrm{yr}$ in April-June (Figs. 3b-d), while those in the south-central 
(a) 1950-2009 (60-year)

(i) MAR

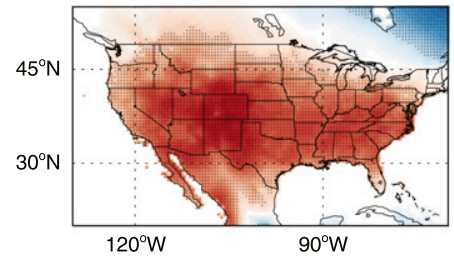

(ii) APR

(iii) MAY

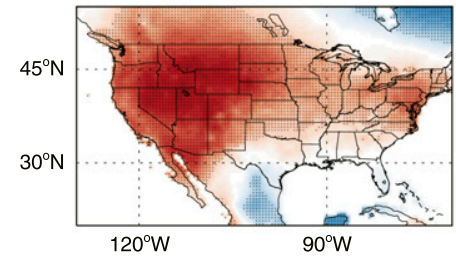

(iv) JUN
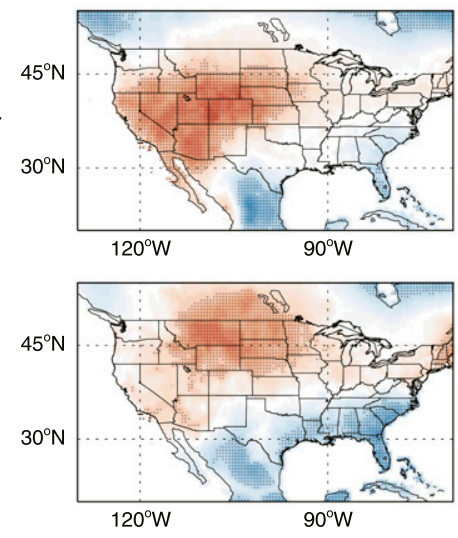

(b) 1950-1979 (30-year)
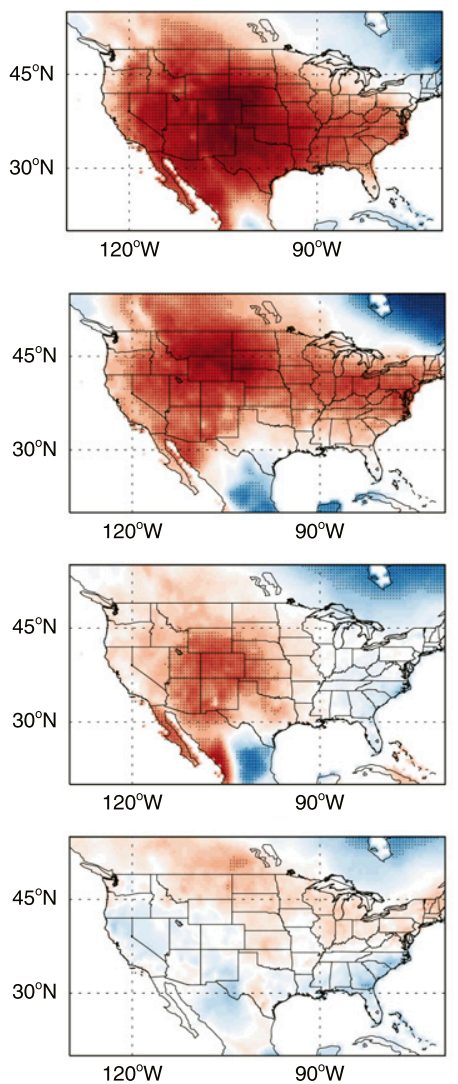

(c) 1980-2009 (30-year)
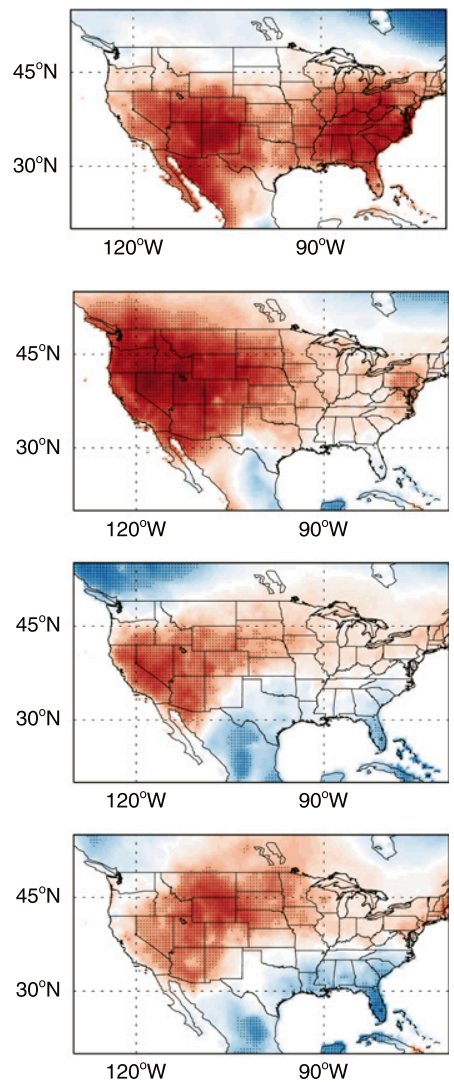

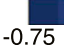

FIG. 2. As in Fig. 1, but for the CRU dataset.

United States were weakened. These results are observed not only in CRU but also in R1 (not shown), suggesting slight westward shifts in the NAO- $T_{\text {ave }}$ correlation centers in the post-1979 period compared to the pre-1979 period. The significant positive correlations in the SWUS consistently observed from March through June in the later period can also be identified from the NARR (not shown).

The time series of the NAO and $T_{\text {ave }}$ (both detrended) in the central SWUS region for each month are displayed in Fig. 4a. The central SWUS region, indicated by the rectangular box in Fig. $1 \mathrm{a}\left(35^{\circ}-42^{\circ} \mathrm{N}\right.$, $120^{\circ}-109^{\circ} \mathrm{W}$ ), includes the areas where significant correlations persist during the early warm season. The time series indicates that the monthly temperature anomalies in the region are generally in phase with the NAO in the early warm season. Their connections are likely to be stronger in the later period, especially in June, as seen in the intensification of the relationship in the later 30-yr period in Figs. 1 and 2. This feature is also supported by the 30-yr moving correlation coefficients in Fig. 4b. There are gradual upward trends in the moving correlation coefficients in April, May, and June. In March, there is a downward trend overall, but the magnitudes of the correlations are significantly high. These features suggest that early warm season temperature variability in the SWUS covaries with NAO variability more dominantly in recent decades. Considering the fact that the PDO is the main contributing factor to climate shift in the late 1970s, these results imply multidecadal modulations of large-scale ocean-atmosphere circulations on the NAO-related characteristics, especially in the SWUS and central U.S. regions.

Considering also a possible influence of other climate indices on the temperatures in spring or summer (e.g., Leathers et al. 1991; Wolter et al. 1999), we investigated the relationships between the SWUS surface temperatures and multiple atmospheric/oceanic indices. Figure 5 shows the correlation results for ENSO 
(a) MAR

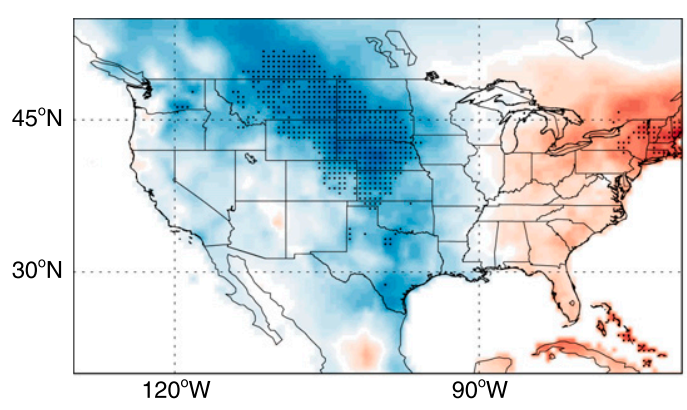

(c) MAY

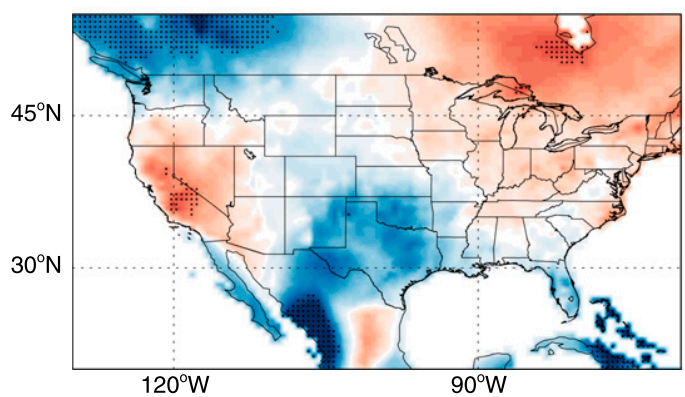

(b) APR

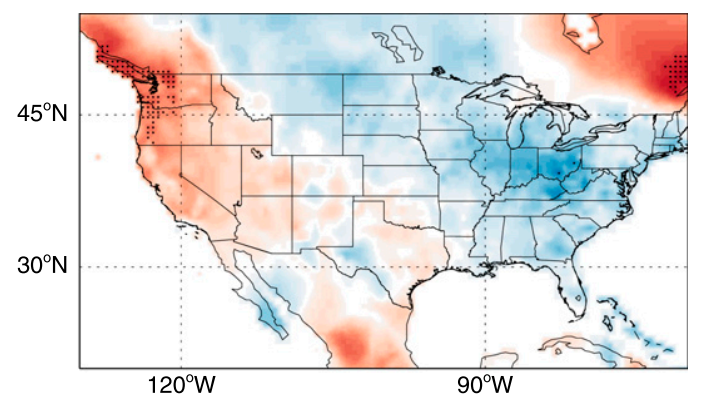

(d) JUN

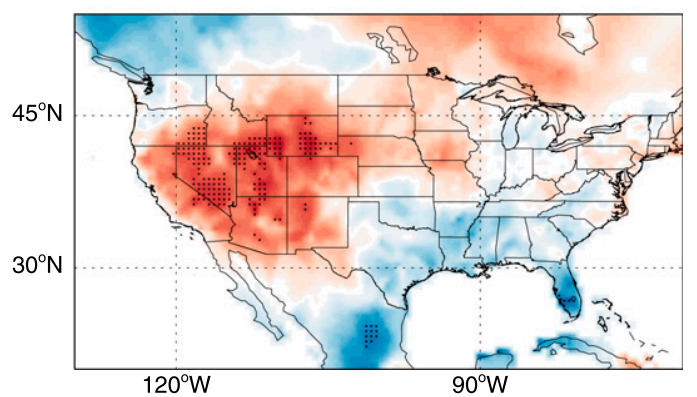

FIG. 3. Differences of NAO- $T_{\text {ave }}$ correlations between the pre-1979 period (1950-79) and the post-1979 period (1980-2009), and their statistical significances at the 95\% confidence level using bootstrap resampling (see section 2 for more detailed information).

leading $T_{\text {ave }}$ by 1 month, which is the time lag exhibiting the strongest relationship. The results display the spatial dipole structure of the ENSO relationship (i.e., positive and negative correlations in the northern and southern part of the western continent of North America, respectively). The spaces and magnitudes of the negative correlations in the south are generally increased in the post-1979 period (Fig. 5c), compared to the pre-1979 period (Fig. 5b). However, the negative correlation in the south mostly prevails in Texas and its vicinity.

Figure 6 displays the 60 -yr correlations of $T_{\text {ave }}$ with the PDO, AMO, and PNA. The strongest correlations can be found with a 1-month (zero) lag for the PDO (AMO and AO). In Fig. 6a, the correlation patterns of the PDO are similar to those of ENSO (Fig. 5a), but to a lesser degree. The highly localized positive correlations along the Pacific coast, including Baja California, are likely to be associated with positive (negative) SST anomalies in the eastern Pacific during the positive (negative) PDO years. The negligible correlations in most of the interior regions of the SWUS in Figs. 5 and 6 indicate that the SWUS region appears to be less affected by ENSO than the PDO in the early warm season and that the significant roles of SST variability in the Pacific on the winter precipitation and temperature in the SWUS are confined to the cool season.

The AMO index (Fig. 6b) shows only marginally significant correlation strength over the limited locations of the SWUS in most months. One point to note here is the negative signs in the SWUS. One may think that these negative signs are in contrast to the positive signs of the correlations between the NAO and $T_{\text {ave }}$ (Figs. 1 and 2), although both the NAO and AMO are variabilities of the North Atlantic Ocean. However, this is not unexpected when considering the different natures of the NAO and AMO; that is, the NAO is an atmospheric internal variability with a dipole structure between the subtropical and the northern Atlantic Ocean, while the AMO is an oceanic (SST) variability between the tropics and Greenland. In fact, the NAO is negatively correlated with the AMO with zero time lag in winter, possibly because of the relatively long AMO lead time ( $\sim 15$ months) to the NAO (Peings and Magnusdottir 2014).

For the PNA (Fig. 6c), the typical northwestsoutheast dipole patterns of PNA-temperature correlations in the North American continent (Leathers et al. 1991) are also found in our analysis. The spatial patterns of the PNA correlations resemble those of the ENSO correlations. However, correlations are weak in 
(a) NAO vs Tave

(i) MAR

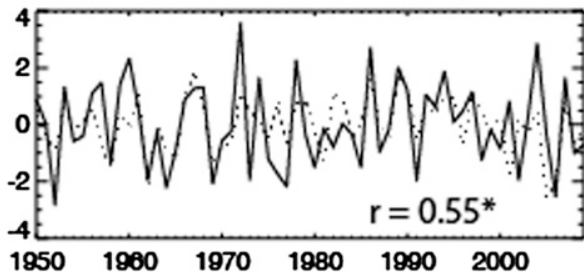

(ii) APR

(iii) MAY

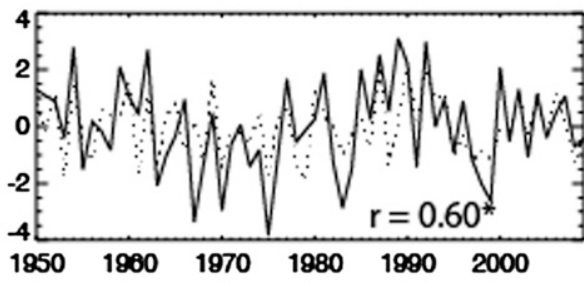

(iv) JUN
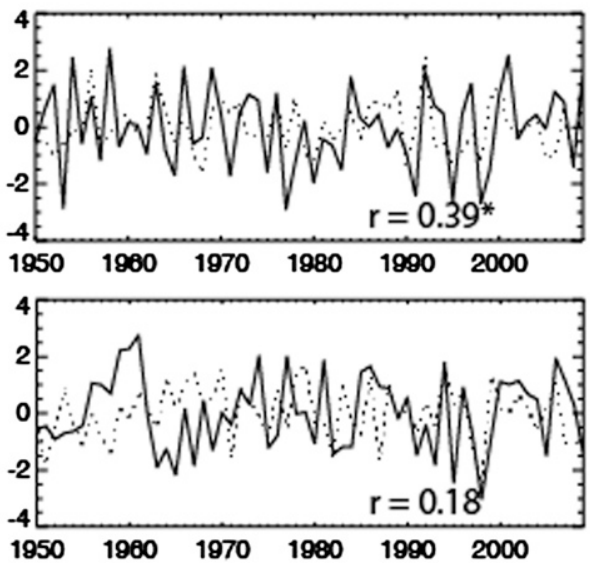

(b) 30-year moving correlation
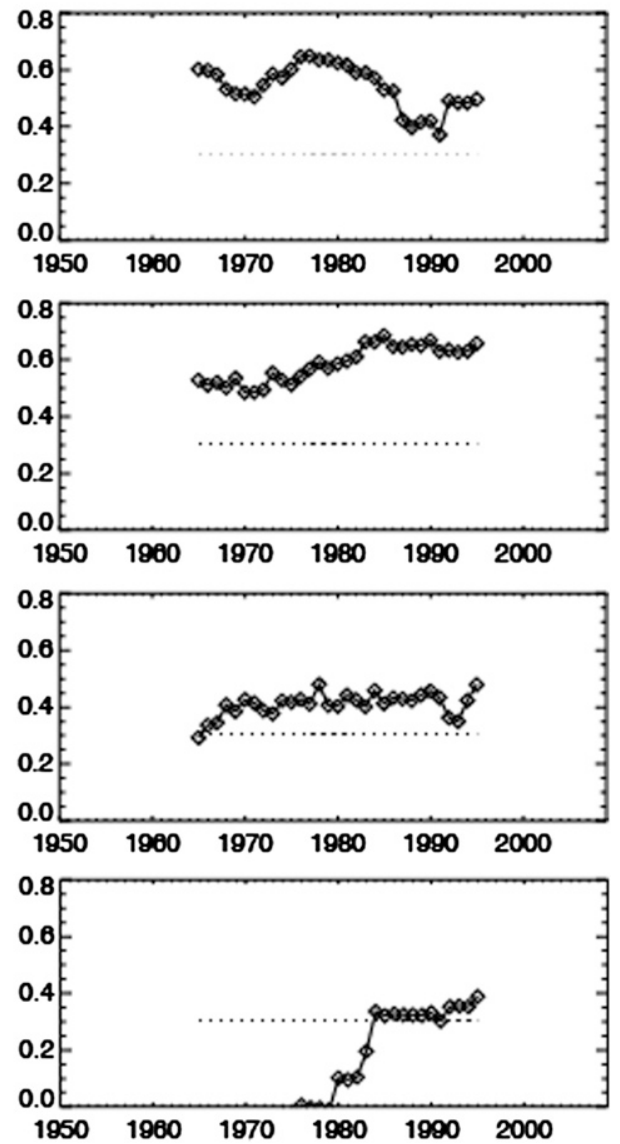

FIG. 4. The time series of (a) the NAO index (dotted) and the mean surface temperature (solid) (both detrended) in the central SWUS region indicated in the rectangular box in Fig. 1a(i), with correlation coefficient $r$, and (b) the 30-yr moving correlation coefficients in each month. Asterisks in (a) and dotted lines in (b) indicate significance of the correlation at the $95 \%$ confidence level.

the SWUS regions, except in New Mexico. The correlations for the SOI are similar to those for ENSO (not shown).

The results of correlations shown in Figs. 5 and 6 are not as robust as the results of the NAO, especially over the central part of our study domain, which shows significant correlations consistently during the early warm season. The strong NAO correlations occur in between the northwestern and south-central United States, where the significant ENSO (or PNA) correlations are observed. One exception is found with the $\mathrm{AO}$, which is tightly correlated in most of the early warm season (March, May, and June). This is because of the close resemblance of AO characteristics with NAO characteristics (Thompson and Wallace 1998; Thompson et al. 2000). Furthermore, as shown in Figs. 5a and 6a, 1- or 2-month lag correlations do not enhance the magnitudes of the correlations substantially.
We also tested whether an additional index as the second predictor in addition to the NAO can improve the predictability of the temperature variability in a multiple linear regression model, but we found no critical improvement of the model using any of the indices. These results emphasize the prevalent linkage of the NAO with spring temperatures in the SWUS region.

\section{b. Atmospheric processes responsible for the NAO-temperature linkages}

The NAO-temperature link can be attributed to the presence of upper-tropospheric anticyclones over the WUS associated with the positive NAO phase. Figure 7 shows the correlations between the NAO and $500-\mathrm{hPa}$ geopotential heights for the entire 60 years (Fig. 7a) and the pre- and post-1979 periods (Figs. $7 \mathrm{~b}$ and $7 \mathrm{c}$, respectively). In Fig. 7a, the positive correlations are 
(a) 1950-2009 (60-year)

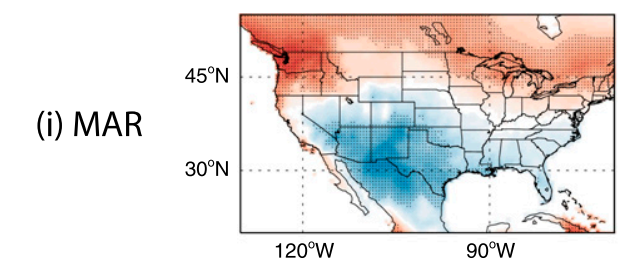

(ii) APR

(iii) MAY

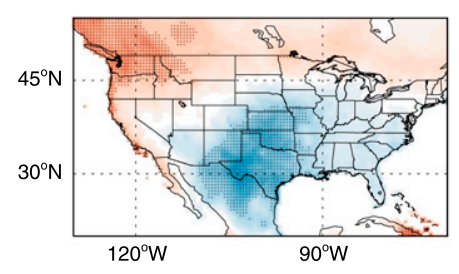

(iv) JUN
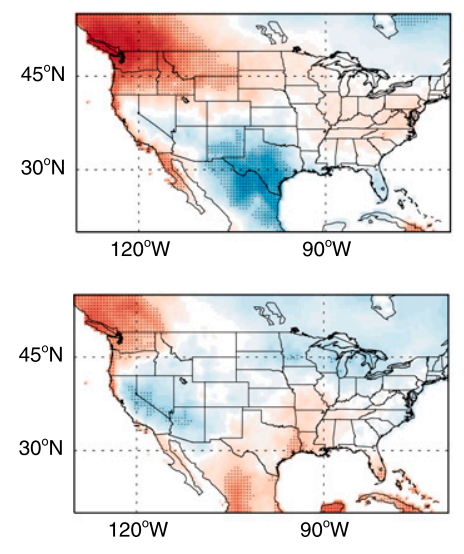

(b) 1950-1979 (30-year)
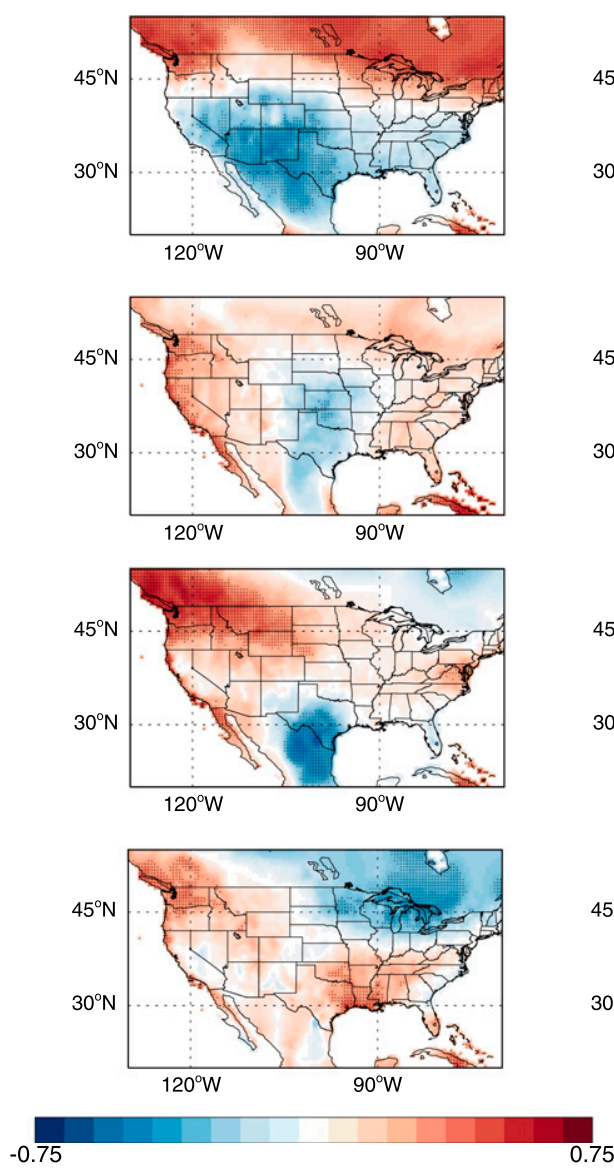

(c) $1980-2009$ (30-year)
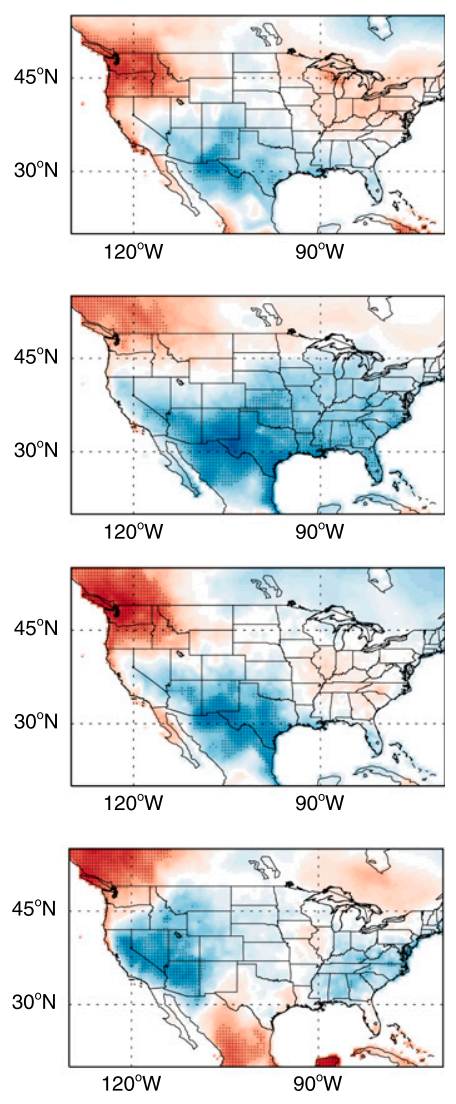

FIG. 5. As in Fig. 2, but for ENSO-temperature correlations. A 1-month time lag (ENSO leading $T_{\text {ave }}$ ) is applied.

dominant over the contiguous United States and northern Mexico (March), the WUS and central United States (April and May), and the north-central United States and south-central Canada (June). These regions correspond to the regions where the NAO- $T_{\text {ave }}$ correlations are dominant (Figs. 1a and 2a), implying that warmer conditions in positive NAO years in the SWUS prevail in the presence of upper-tropospheric anticyclones over the region. The regional coherence between the NAO-temperature relationships and the NAOheight relationships is also found in pre- and post-1979 periods [see Figs. 7b, 1b (or Fig. 2b) and Figs. 7c, 1c (or Fig. 2c)].

In Fig. 7a, we observe that the positive correlations in the United States are usually accompanied by positive correlations over the North Pacific (near the Bering Sea) and the northwestern Atlantic, as well as negative correlations in the Gulf of Alaska. Most of the correlations over these regions are statistically significant. This pattern indicates that the NAO-related characteristics in the upper troposphere are not limited to the areas adjacent to the North Atlantic, such as the eastern United States and western Europe; they are also obvious in upstream regions, such as the WUS and the North Pacific. Additionally, this is evident in both $30-y r$ periods (Figs. 7b,c), although the negative correlations in the Gulf of Alaska are sometimes less pronounced.

Figures $7 \mathrm{~b}$ and $7 \mathrm{c}$ indicate that the NAO-height correlation centers in the continental U.S. region exhibit westward shifts in the post-1979 period compared to the pre-1979 period, especially in April, May, and June. During these months, as shown above, the NAO- $T_{\text {ave }}$ correlation center also moves westward (Figs. 1b,c and $2 b, c)$, suggesting that changes in the upper-tropospheric geopotential height field induce changes in the surface temperature field. Although it requires further investigation, Fig. 7 also captures the westward shift of the NAO-height correlation center over the Atlantic in March, May, and June. In addition, we have found consistent shifts in the correlation field between the 
(a) PDO (60-year)

(i) MAR

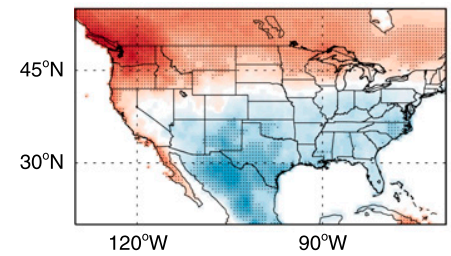

(ii) APR

(iii) MAY
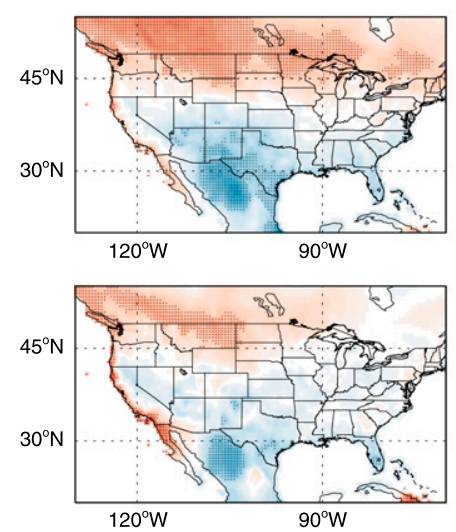

(iv) JUN

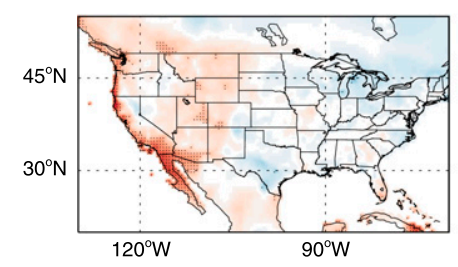

(b) AMO (60-year)
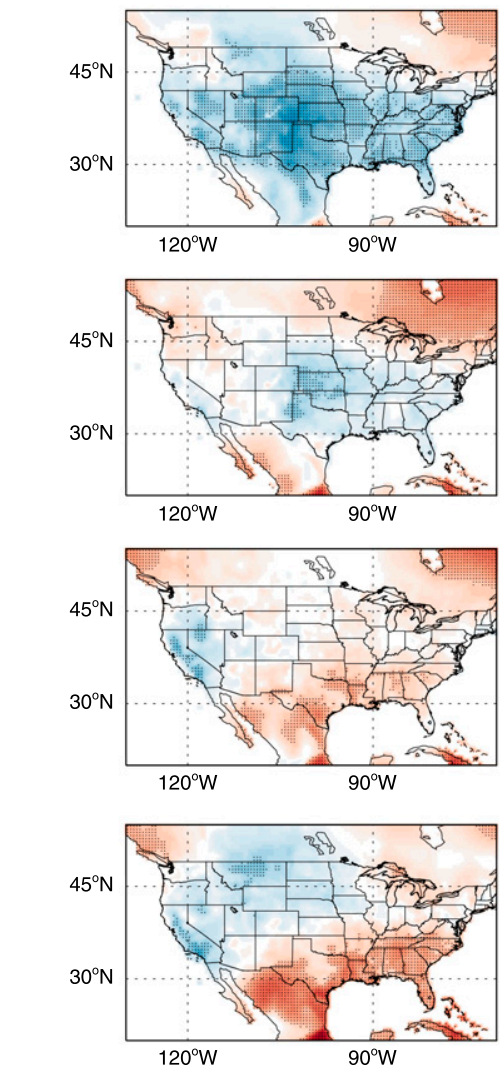

(c) PNA (60-year)
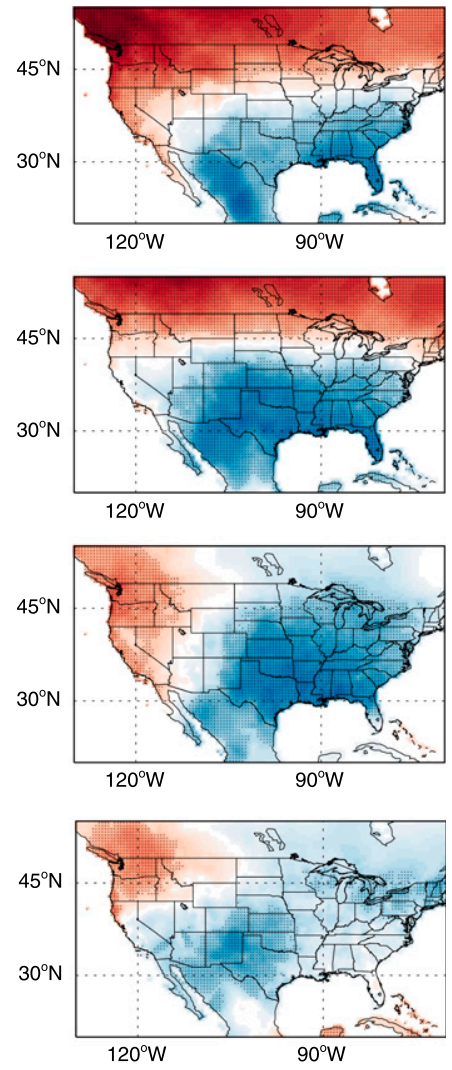

$-0.75$

0.75

FIG. 6. As in Fig. 2, but for the temperature correlations with the (a) PDO, (b) AMO, and (c) PNA for the 60-yr period (1950-2009). A 1-month time lag is applied for the PDO (PDO leading $T_{\text {ave }}$ ), while instantaneous correlations are shown for the AMO and PNA.

NAO and surface pressure (not shown). These results imply that intensification of the NAO-SWUS temperature coupling in the post-1979 period is related to the westward shift of the NAO-related characteristics of the atmosphere and ocean.

For detailed examinations of the modification of SWUS surface temperature by upper-level height anomalies in positive or negative NAO years, we performed a composite analysis of various atmospheric variables (e.g., wind vectors, vertical motion, total cloud fractions, and surface shortwave radiation flux) for extremely positive and negative NAO years. The extreme positive (negative) NAO years are selected as the years of the detrended NAO index larger (smaller) than 1.22 $(-1.34)$ that correspond to the top (bottom) $15 \%$ of the probability of density function of the NAO index between March and June. The extreme NAO years, as shown in Table 1, vary from month to month, as the NAO index is subject to strong month-to-month variability. Here, we show the results for the month of April only because of the similarity in results for the other months.

For the composites of geopotential height in Fig. 8a(i), the positive anomaly-inducing anticyclonic circulations occur over the WUS in the extreme positive years of the NAO. This positive anomaly is associated with another positive anomaly over the North Pacific and the Atlantic and with a negative height anomaly over the Gulf of Alaska. Similar, but opposite, patterns are also found during the extreme negative NAO years [Fig. 8a(ii)]. These anomaly patterns are statistically significant, except for the positive anomaly over the Gulf of Alaska in the negative years. These characteristics of the height field suggest that the propagation of Rossby waves may be responsible for the development of the positive height anomalies over the WUS during the positive NAO phase (Benedict et al. 2004; Rivière and Orlanski 2007; Woollings et al. 2008). Benedict et al. (2004) asserted that this uppertropospheric height field is caused by quasi-stationary 
(a) 1950-2009 (60-year)

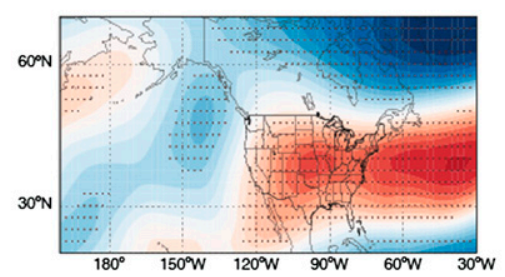

(i) MAR

(ii) APR
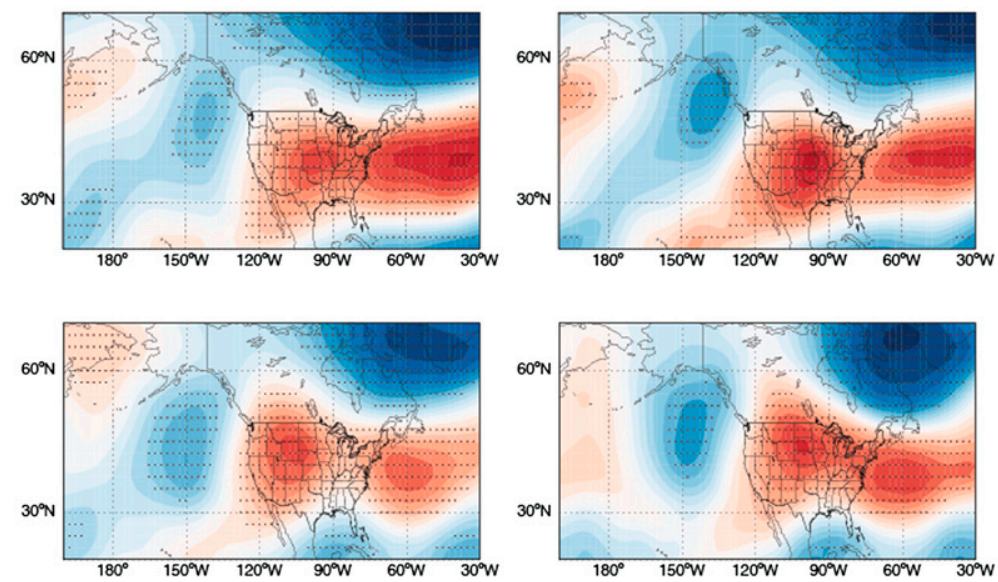

(b) 1950-1979 (30-year)

(c) 1980-2009 (30-year)
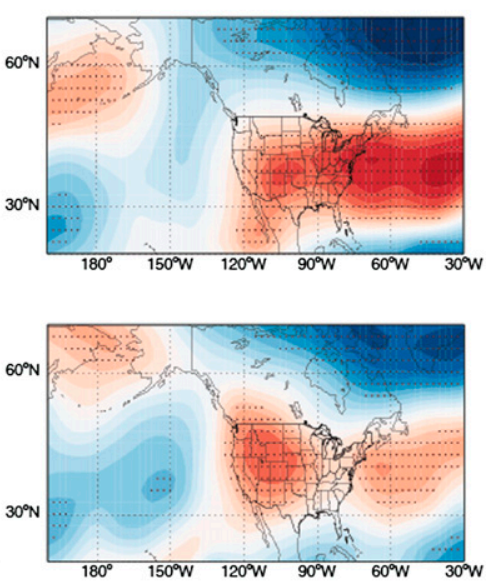

(iii) MAY
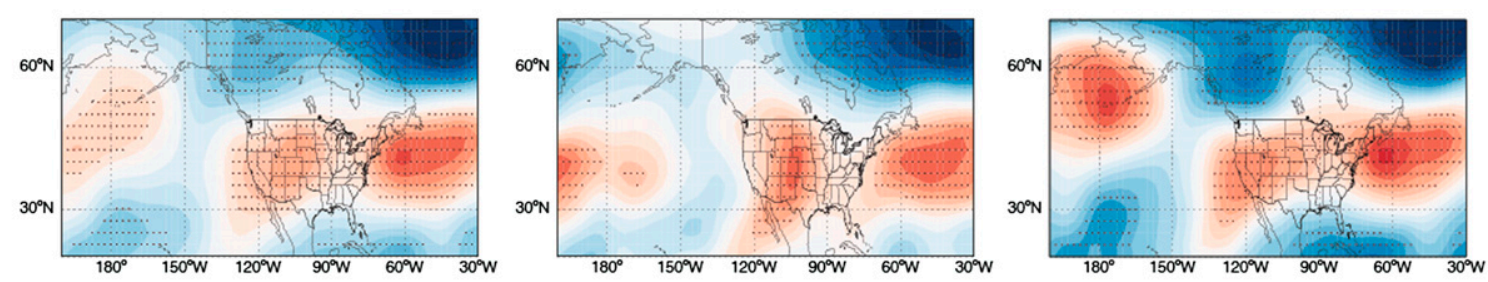

(iv) JUN
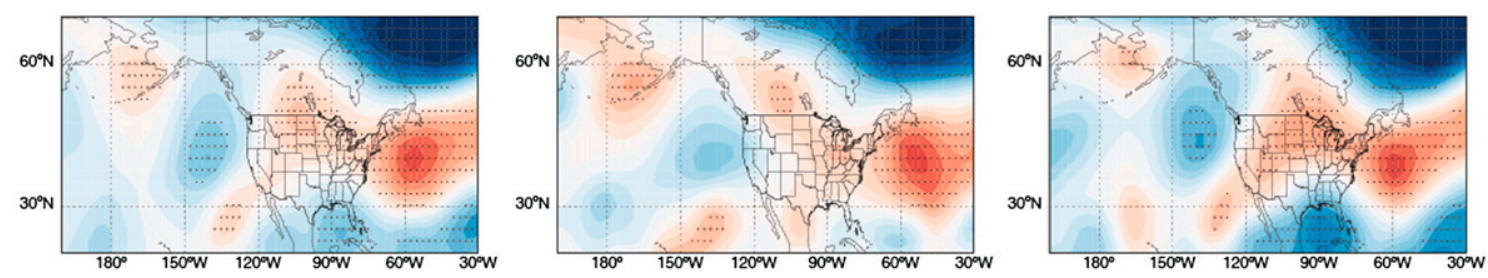

$-0.75$

FIG. 7. As in Fig. 1, but between NAO and the geopotential height at $500 \mathrm{hPa}$.

Rossby wave propagation from the Pacific Ocean to the Atlantic Ocean, the primary mechanism underlying the positive NAO phase over the Atlantic Ocean. The locations of the three positive (negative) height anomalies in Fig. 8a(i) [Fig. 8a(ii)] correspond to the positive centers of the Rossby wave propagations in their analysis.

Upper-level geopotential height anomalies tend to strongly affect surface temperatures primarily via two pathways. First, while westerlies at $850 \mathrm{hPa}$ are climatologically dominant over the SWUS states in April (not shown), the wind patterns can be substantially modified by the upper-level anomalous circulations in the extreme NAO years. Anomalous wind directions at $850 \mathrm{hPa}$ are almost opposite in the positive (i.e., anticyclonic) and negative (i.e., cyclonic) extreme NAO years [Figs. $8 \mathrm{~b}(\mathrm{i})$ and $8 \mathrm{~b}(\mathrm{ii})$, respectively]. During the

TABLE 1. The composite years of the positively and negatively extreme NAO years within the 60-yr period (1950-2009) for each month. The number of years is indicated in parentheses.

\begin{tabular}{lll}
\hline \hline & \multicolumn{1}{c}{ Lowest } & \multicolumn{1}{c}{ Highest } \\
\hline Mar & $1958,1962,1969,2001$, 2005, and 2006 (6) & 1967,1986, and 1989 (3) \\
Apr & $1953,1961,1963,1970,1975,1979$, and 1988 (7) & $1954,1960,1969,1980,1987,1990$, and 1992 (7) \\
May & $1968,1980,1990,1995$, and 2008 (5) & $1956,1963,1992,2000$, and 2009 (5) \\
Jun & $1951,1958,1971,1982,1987$, and 1998 (6) & $1967,1970,1978,1979,1986,1994$, and 1999 (7) \\
\hline
\end{tabular}


(i) Positive NAO years

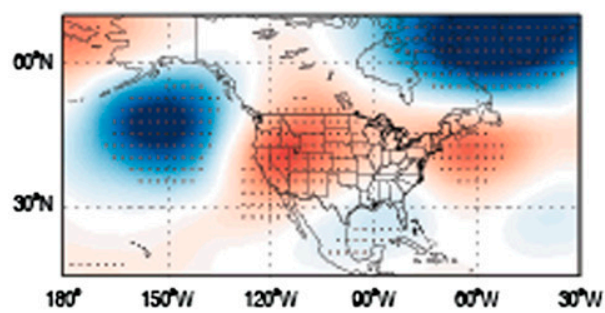

(b) Wind

\section{(c) Omega}

(d) Rad

(e) Ts
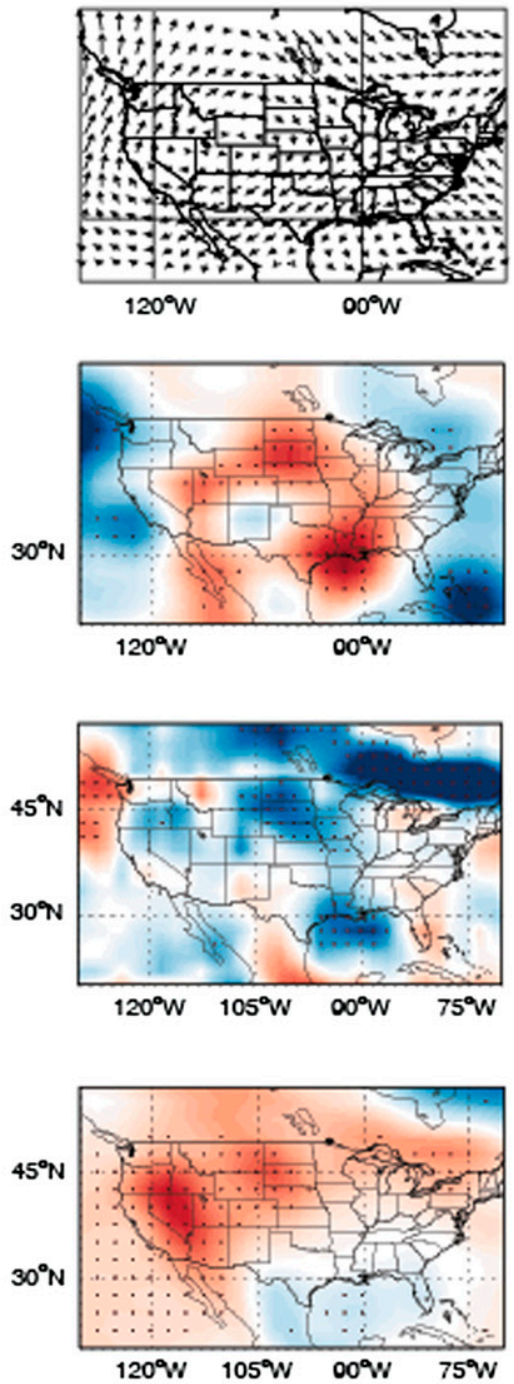

(ii) Negative NAO years
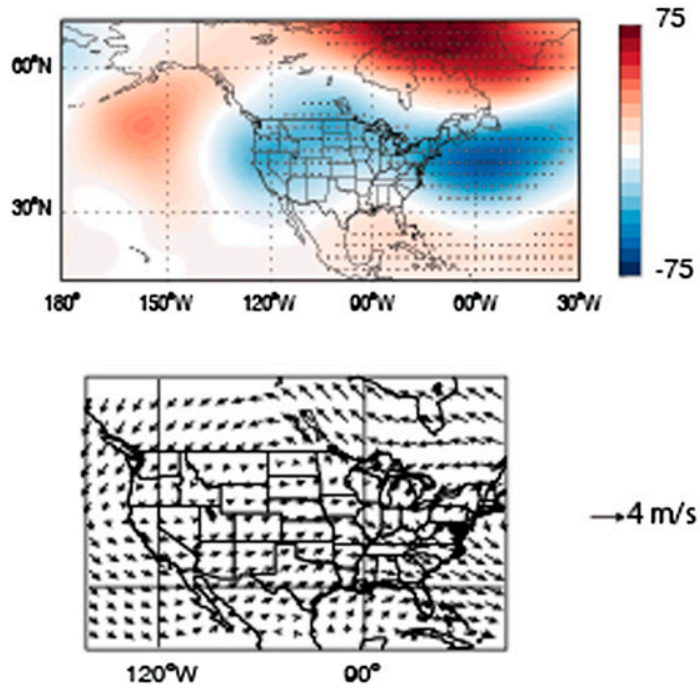

$\rightarrow 4 \mathrm{~m} / \mathrm{s}$
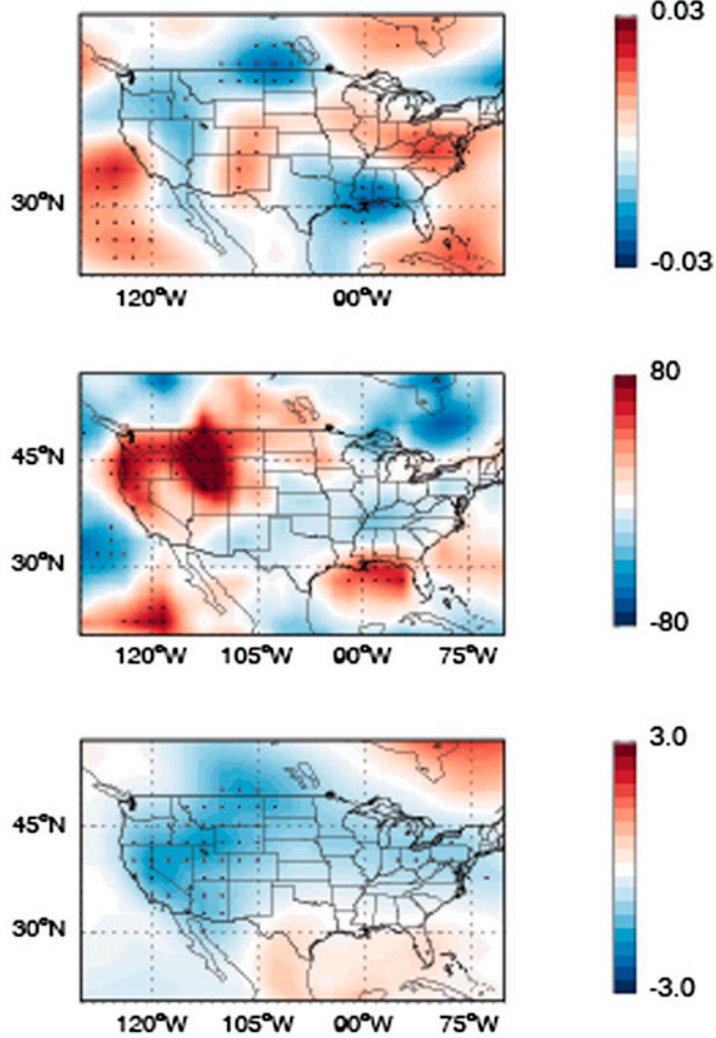

FIG. 8. Monthly anomalies (April) of (a) the geopotential height at $500 \mathrm{hPa}$, (b) vector winds at $850 \mathrm{hPa}$, (c) vertical motion (dp/dt), (d) net shortwave radiation flux at surface $\left(\mathrm{W} \mathrm{m}^{-2}\right)$, and (e) mean surface temperature $\left({ }^{\circ} \mathrm{C}\right)$ of the extreme (i) positive and (ii) negative NAO years. The extreme positive and negative NAO years are given in Table 1 . The grids with dots indicate statistical significance at the $95 \%$ confidence level. 
(a) Tmax

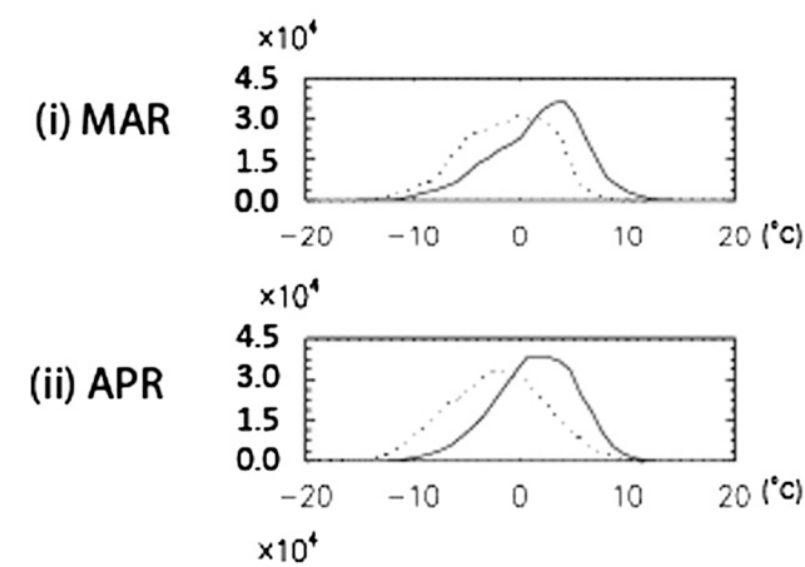

(iii) MAY

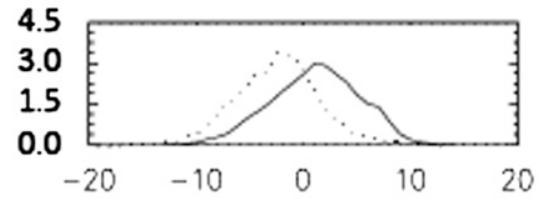

$\times 10^{4}$

(iv) JUN

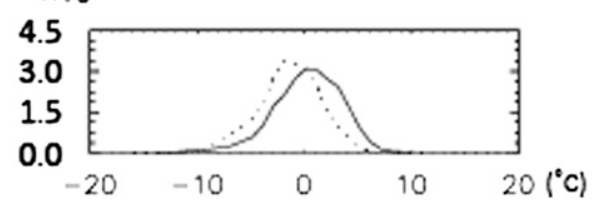

(b) Tmin
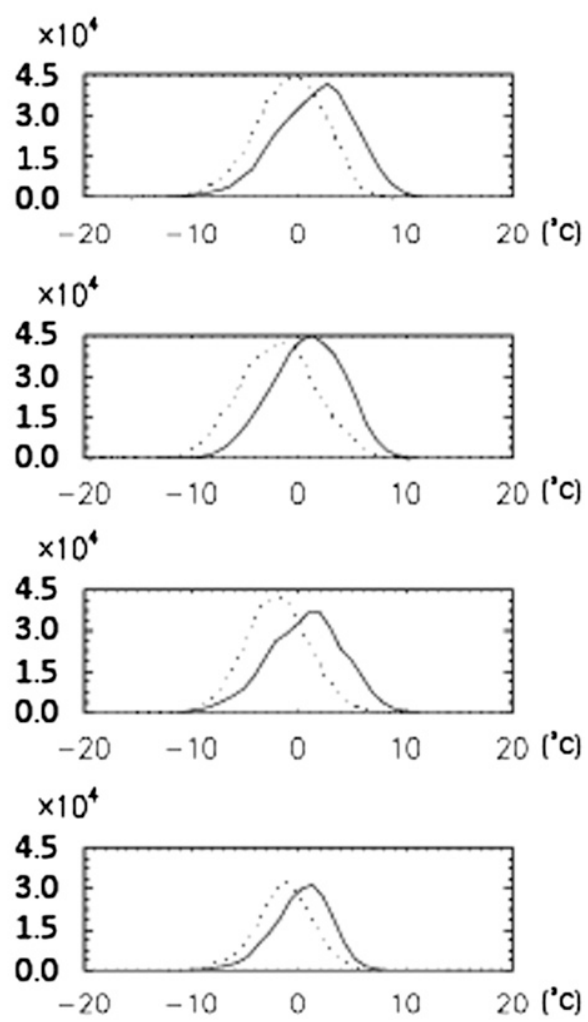

FIG. 9. PDFs with $0.2^{\circ} \mathrm{C}$ bin size of (a) $T_{\max }$ and (b) $T_{\min }$ of the NARR (1980-2009) for the five highest (solid lines) and lowest (dashed lines) NAO composite years presented in Table 2. Only the grids in the SWUS with significant correlation at the $95 \%$ confidence level are considered. The $y$ axis represents density.

extreme positive NAO years, because of the anticyclonic wind pattern, anomalous southerlies, southeasterlies, or easterlies prevail in the SWUS region, which prevent cool air inflows into these regions, resulting in higher surface temperatures [Fig. 8b(i)]. In the extreme negative NAO years [Fig. 8b(ii)], anomalous northwesterlies or westerlies linked with the cyclonic wind pattern in the SWUS are dominant, stimulating cold advection into the region to reduce surface temperatures [Fig. 8b(ii)]. This wind effect appears to be more prominent in the southwestern part of the upper-level anticyclones.

Second, temperature variations are also affected by cloud fraction and shortwave radiation. In extremely positive NAO years, an enhanced sinking motion prevails over the WUS and central United States (Nevada, Wyoming, Utah, South Dakota, and Nebraska) [Fig. 8c(i)], suppressing precipitation and cloud cover. Associated increases in surface insolation [Fig. 8d(i)] are consistent with surface temperature increases in the central part of the WUS and the north-central United States [Fig. 8e(i)]. In extremely negative NAO years, the opposite processes (i.e., more upward motion, higher cloud cover, and less surface insolation) over the WUS and north-central United States/Canada [Figs. 8b(ii), $8 \mathrm{c}(\mathrm{ii})$, and $8 \mathrm{~d}(\mathrm{ii})$ ] contribute to lower surface temperatures [Fig. 8e(ii)]. This solar radiation effect is more pronounced during daytime, which may be one of the reasons for the observed stronger NAO- $T_{\max }$ correlations compared to the observed $\mathrm{NAO}-T_{\min }$ correlations.

While more analysis is required to quantify the relative contributions between these two effects (i.e., the wind effect and the radiation effect), a combination of these two effects is likely to determine the surface temperature anomaly pattern. This will be a subject of future work. In several southeastern states (western Texas, Louisiana, and Mississippi) and the adjacent Gulf of Mexico area [Fig. 8e(i)], for example, temperature anomalies are negligible in the positive NAO years, despite the presence of descending motions [Fig. 8c(i)] and enhanced solar radiation [Fig. 8d(i)]. This may be as a result of cold advection by anomalous northerly winds [Fig. 8b(i)]. 
TABLE 2. The composite years of the five highest and lowest NAO years within the second 30-yr period (1980-2009) for each month.

\begin{tabular}{lcr}
\hline & Lowest & Highest \\
\hline Mar & $2005,2006,2001,1981$, and 1984 & $2007,1990,1997,1986$, and 1989 \\
Apr & $1988,2008,1997,1999$, and 1983 & $2002,2004,1992,1987$, and 2006 \\
May & $2008,1990,1980,1995$, and 1998 & $1987,1989,2000,2009$, and 1992 \\
Jun & $1998,1987,1982,1997$, and 2008 & $2006,1983,1999,1986$, and 1994 \\
\hline
\end{tabular}

\section{c. Modulation of mean and extreme daily temperatures in the early warm season}

While monthly mean surface temperatures in the SWUS appear to be strongly modulated by the NAO variability in the early warm season, the NAO may also be linked with daily extremes in the SWUS. To test this hypothesis, we use the NARR dataset (1980-2009), because neither the R1 nor the CRU dataset provides the daily $T_{\max }$ and $T_{\min }$. Figure 9 displays the probability density functions (PDFs) of NARR daily $T_{\max }$ and $T_{\min }$ (detrended) in the five highest and lowest NAO years in the later 30-yr period (Table 2). The five highest (lowest) NAO years in this period approximately correspond to the years with the highest (lowest) $15 \%$ of the PDF of the NAO index from March to June. In calculating these PDFs, only the grid points in the SWUS with correlation coefficients exceeding the $95 \%$ level are included. Figure 9 demonstrates substantial changes in the shape of the PDFs, especially in March, April, and May. In positive NAO months, both $T_{\max }$ and $T_{\min }$ are higher than those of the negative NAO months. Generally, the PDF peaks are shifted to the warmer side in the positive NAO months, compared with the negative NAO months. Monthly mean differences of $T_{\max }\left(T_{\min }\right)$ between the highest and lowest NAO years vary between $1.7^{\circ}$ and $3.65^{\circ} \mathrm{C}\left(1.66^{\circ}\right.$ and $\left.2.85^{\circ} \mathrm{C}\right)$ by month, which are statistically significant (e.g., $p$ value $<0.000$ ) (Table 3 ).

The extreme values of $T_{\max }$ and $T_{\min }$ are also affected by the NAO phase. Tables 4 and 5 show the mean values of the extreme $T_{\max }$ and $T_{\min }$ values (5th and 95th percentile values) and their monthly differences. The highest NAO years introduce higher extremes of $T_{\max }$ than the lowest NAO years in all the months, with the differences ranging between $1.61^{\circ}$ and $3.51^{\circ} \mathrm{C}$ for the 95th percentile extremes (between $0.58^{\circ}$ and $4.63^{\circ} \mathrm{C}$ for the 5 th percentile extremes). These differences are statistically significant, as indicated by the $p$ values, suggesting that the NAO not only affects the average temperature but that it also affects the extremes of $T_{\max }$. The extreme $T_{\min }$ values also show positive responses to NAO (Table 5). The differences are in the range of $1.07^{\circ}-3.50^{\circ} \mathrm{C}\left(1.44^{\circ}-3.24^{\circ} \mathrm{C}\right)$ for the 95 th $(5$ th $)$ percentile extremes. Impacts of the NAO on extreme winter daily temperatures have been reported in many parts of the Northern Hemisphere (Brown et al. 2008; Loikith and Broccoli 2012, 2014), and our results suggest that the NAO significantly modulates the daily surface air temperature means and extremes in the SWUS during the early warm season.

\section{Discussion and conclusions}

The present study shows that March-June surface temperatures in the SWUS are strongly modulated by NAO variability. The high interannual correlations of surface temperatures with the NAO are primarily through the development of upstream anticyclones in the WUS region when a positive NAO phase is established over the Atlantic Ocean. These anticyclones tend to enhance surface insolation and alter lowertropospheric wind patterns, eventually increasing both the daily mean temperature and the extreme temperatures. This link exists only in the early warm season March-June over the SWUS because of the northeastward shift of the NAO center from winter to summer (Portis et al. 2001; Straile and Stenseth 2007).

Relationships between surface temperatures and other major climate indices (e.g., ENSO, PDO, AMO,

TABLE 3. Monthly mean $T_{\max }$ and $T_{\min }$ (detrended) $\left({ }^{\circ} \mathrm{C}\right)$ of the highest and lowest NAO years of NARR and their differences. The $p$ values of all the differences were less than 0.0001 .

\begin{tabular}{|c|c|c|c|c|c|c|}
\hline & \multicolumn{3}{|c|}{$T_{\max }$} & \multicolumn{3}{|c|}{$T_{\min }$} \\
\hline & Highest NAO & Lowest NAO & Difference & Highest NAO & Lowest NAO & Difference \\
\hline Mar & 2.15 & -0.88 & 3.03 & 2.02 & -0.47 & 2.49 \\
\hline Apr & 1.83 & -1.82 & 3.65 & 1.33 & -1.52 & 2.85 \\
\hline May & 1.62 & -2.0 & 3.62 & 1.13 & -1.48 & 2.61 \\
\hline Jun & 0.73 & -0.97 & 1.70 & 0.77 & -0.89 & 1.66 \\
\hline
\end{tabular}


TABLE 4. Mean values $\left({ }^{\circ} \mathrm{C}\right)$ of extreme daily $T_{\max }$ less than the 5 th and greater than the 95 th percentile (thresholds in parentheses) of the highest and lowest NAO years of NARR and their differences. The $p$ values of all the differences were less than 0.0001 .

\begin{tabular}{|c|c|c|c|c|c|c|}
\hline & \multicolumn{3}{|c|}{$<5 \%$} & \multicolumn{3}{|c|}{$>95 \%$} \\
\hline & Highest NAO & Lowest NAO & Difference & Highest NAO & Lowest NAO & Difference \\
\hline Mar & $-7.53(-5.51)$ & $-9.92(-7.98)$ & 2.38 & $9.72(8.23)$ & $6.20(4.99)$ & 3.51 \\
\hline Apr & $-6.80(-4.97)$ & $-11.44(-9.38)$ & 4.63 & $8.92(7.68)$ & $7.19(5.61)$ & 1.73 \\
\hline May & $-6.99(-5.35)$ & $-10.21(-8.38)$ & 3.21 & $9.27(8.05)$ & $6.49(4.37)$ & 2.78 \\
\hline Jun & $-7.26(-4.96)$ & $-7.85(-6.43)$ & 0.58 & $6.51(5.42)$ & $4.89(3.74)$ & 1.61 \\
\hline
\end{tabular}

and PNA) show only marginally significant correlation strengths over several locations in our study domain in the 60 -yr period. This is despite the fact that the SST variability in the Pacific Ocean has substantial impacts on the winter precipitation, temperature (Gershunov and Barnett 1998; McCabe and Dettinger 1999), and vegetation ( $\mathrm{Li}$ and Kafatos 2000). One of the reasons for their weak connections in the early warm season may be the offset of the direct and positive effect (e.g., increases of land surface temperature caused by warm surface temperature of the neighboring ocean in the positive ENSO spring) by the indirect and negative effect (e.g., decreases of land surface temperature caused by abovenormal precipitation and less sensible heat flux from the surface in the positive ENSO winters) (Alfaro et al. 2006) because of the slowly varying natures of ENSO or the PDO. In contrast, the responses of surface temperature in the SWUS to NAO-related circulation are direct, with a one-way direction, because NAO is purely an internal variability of the atmosphere (Feldstein 2003; Benedict et al. 2004; Woollings et al. 2008). Predominant impacts of transient atmospheric variability (e.g., PNA) compared to slowly varying oceanic variability (e.g., ENSO) on the daily and monthly temperature extremes of the United States in winter and early spring have also been emphasized in the studies of Loikith and Broccoli (2012, 2014), although the impacts of the PNA are prevalent in the northwestern and southeastern United States, as shown in Fig. 6c of the current study.

We found that the NAO-temperature link has been intensified in the later 30-yr period (1980-2009) compared to the earlier 30-yr period (1950-79), presumably because of the westward shift of the subtropical NAO centers and the upper-level height anomaly centers in the WUS. The multidecadal changes in the NAOtemperature correlations occur not only in the SWUS, but also in the south-central and southeastern United States. In these regions, the correlation intensities in January and February are much weaker in the post-1979 period compared to the pre-1979 period (not shown). These features emphasize spatial variations in the NAO and associated effects in North America and western Europe at diverse time scales ranging from monthly to multidecadal scales.

Findings in this study are critical for the SWUS region, because it is characterized by a semiarid to arid climate with strong temperature variations in spring and fall. Reasons for these shifts are a subject of future studies. The temperature variabilities in late spring and early summer affect human health and agricultural productivity, both directly and indirectly. An example of a direct effect is sudden warming in early summer (e.g., a heat wave), which is a serious concern for human health and wellbeing. Similarly, abnormally low or high temperatures in the growing season can inhibit active crop growth and reduce annual yields of certain crops, such as maize, in the SWUS (Porter and Semenov 2005). The indirect effects include interannual variations in snowmelt related to temperature variability in the spring over the WUS, and water supply for the SWUS (Mote et al. 2005; Stewart et al. 2005). Earlier snowmelt associated with global warming is a serious threat to the security of the water supply in the WUS, both now and in the future. Therefore, the impacts of NAO on temperature variability need to be better understood in the SWUS on

TABLE 5. As in Table 4, but for extreme daily $T_{\min }$.

\begin{tabular}{|c|c|c|c|c|c|c|}
\hline & \multicolumn{3}{|c|}{$<5 \%$} & \multicolumn{3}{|c|}{$>95 \%$} \\
\hline & Highest NAO & Lowest NAO & Difference & Highest NAO & Lowest NAO & Difference \\
\hline Mar & $-6.21(-4.25)$ & $-8.20(-6.25)$ & 1.98 & 8.69 (7.57) & $5.45(4.57)$ & 3.24 \\
\hline Apr & $-5.66(-4.35)$ & $-9.16(-7.39)$ & 3.50 & $7.53(6.48)$ & $5.60(4.39)$ & 1.93 \\
\hline May & $-6.46(-4.88)$ & $-7.53(-6.31)$ & 1.07 & $7.78(6.62)$ & $4.84(3.51)$ & 2.93 \\
\hline Jun & $-5.77(-4.01)$ & $-7.00(-5.61)$ & 1.22 & $5.81(4.80)$ & $4.36(3.36)$ & 1.44 \\
\hline
\end{tabular}


intraseasonal time scales. The intensification of the positive NAO phase under increasing greenhouse gas concentrations and global warming (Gillett et al. 2003; Osborn 2004) emphasizes the crucial need for careful examination of the NAO impacts on weather and climate in the SWUS.

Acknowledgments. This work was supported by NIFA (Award 2011-67004-30224) under the joint NSF-DOEUSDA Earth System Models (EaSM) program.

\section{REFERENCES}

Alfaro, E. J., A. Gershunov, and D. Cayan, 2006: Prediction of summer maximum and minimum temperature over the central and western United States: The role of soil moisture and sea surface temperature. J. Climate, 19, 1407-1421, doi:10.1175/ JCLI3665.1.

Ault, T. R., A. K. Macalady, G. T. Pederson, J. L. Betancourt, and M. D. Schwartz, 2011: Northern Hemisphere modes of variability and the timing of spring in western North America. J. Climate, 24, 4003-4014, doi:10.1175/2011JCLI4069.1.

Barnston, A., and R. E. Livezey, 1987: Classification, seasonality, and persistence of low-frequency circulation patterns. Mon. Wea. Rev., 115, 1083-1126, doi:10.1175/1520-0493(1987)115<1083: CSAPOL $>2.0 . \mathrm{CO} ; 2$.

Benedict, J. J., S. Lee, and S. B. Feldstein, 2004: Synoptic view of the North Atlantic Oscillation. J. Atmos. Sci., 61, 121-144, doi:10.1175/1520-0469(2004)061<0121:SVOTNA $>2.0$.CO;2.

Brown, D. P., and A. C. Comrie, 2004: A winter precipitation 'dipole' in the western United States associated with multidecadal ENSO variability. Geophys. Res. Lett., 31, L09203, doi:10.1029/2003GL018726.

Brown, S. J., J. Caesar, and C. A. T. Ferro, 2008: Global changes in extreme daily temperature since 1950. J. Geophys. Res., 113, D05115, doi:10.1029/2006JD008091.

Curtis, S., 2008: The Atlantic multidecadal oscillation and extreme daily precipitation over the US and Mexico during the hurricane season. Climate Dyn., 30, 343-351, doi:10.1007/ s00382-007-0295-0.

Dettinger, M., D. Cayan, H. Diaz, and D. Meko, 1998: North-south precipitation in western North America on interannual-todecadal timescales. J. Climate, 11, 3095-3111, doi:10.1175/ 1520-0442(1998)011<3095:NSPPIW>2.0.CO;2.

Enfield, D. B., A. M. Mestas-Nuñez, and P. J. Trimble, 2001: The Atlantic multidecadal oscillation and its relation to rainfall and river flows in the continental U.S. Geophys. Res. Lett., 28, 2077-2080, doi:10.1029/2000GL012745.

Feldstein, S. B., 2003: The dynamics of NAO teleconnection pattern growth and decay. Quart. J. Roy. Meteor. Soc., 129, 901-924, doi:10.1256/qj.02.76.

Gershunov, A., and T. Barnett, 1998: Interdecadal modulation of ENSO teleconnections. Bull. Amer. Meteor. Soc., 79, 2715-2726, doi:10.1175/1520-0477(1998)079<2715: IMOET $>2.0 . \mathrm{CO} ; 2$

Gillett, N. P., H. F. Graf, and T. J. Osborn, 2003: Climate change and the North Atlantic Oscillation. The North Atlantic Oscillation: Climatic Significance and Environmental Impact, Geophys. Monogr., Vol. 134, Amer. Geophys. Union, 193-209.

Goldenberg, S. B., C. W. Landsea, A. M. Mestas-Nuñez, and W. M. Gray, 2001: The recent increase in Atlantic hurricane activity:
Causes and implications. Science, 293, 474-479, doi:10.1126/ science. 1060040

Higgins, R. W., A. Leetmaa, Y. Xue, and A. Barnston, 2000: Dominant factors influencing the seasonal predictability of U.S. precipitation and surface air temperature. J. Climate, 13, 3994-4017, doi:10.1175/1520-0442(2000)013<3994: DFITSP $>2.0 . \mathrm{CO} ; 2$.

Hurrell, J. W., 1995: Decadal trends in the North Atlantic Oscillation and relationships to regional temperature and precipitation. Science, 269, 676-679, doi:10.1126/ science.269.5224.676.

— ciated with the North Atlantic Oscillation. Climatic Change, 36, 301-326, doi:10.1023/A:1005314315270.

Jones, P. D., T. Jónsson, and D. Wheeler, 1997: Extension to the North Atlantic Oscillation using early instrumental pressure observations from Gibraltar and south-west Iceland. Int. J. Climatol., 17, 1433-1450, doi:10.1002/ (SICI)1097-0088(19971115)17:13<1433::AID-JOC203>3.0.CO;2-P.

Kalnay, E., and Coauthors, 1996: The NCEP/NCAR 40-Year Reanalysis Project. Bull. Amer. Meteor. Soc., 77, 437-471, doi:10.1175/1520-0477(1996)077<0437:TNYRP>2.0.CO;2.

Kapala, A. H., H. Mächel, and H. Flohn, 1998: Behaviour of the centres of action above the Atlantic since 1881. Part II: Associations with regional climate anomalies. Int. J. Climatol., 18, 23-36, doi:10.1002/(SICI)1097-0088(199801)18: $1<23:: A I D-J O C 226>3.0 . C O ; 2-7$.

Knight, J. R., C. K. Folland, and A. A. Scaife, 2006: Climate impacts of the Atlantic multidecadal oscillation. Geophys. Res. Lett., 33, L17706, doi:10.1029/2006GL026242.

Larcher, W., 1995: Physiological Plant Ecology. Springer, 506 pp. Leathers, D. J., B. Yarnal, and M. A. Palecki, 1991: The Pacific/North American teleconnection pattern and United States climate. Part I: Regional temperature and precipitation associations. J. Climate, 4, 517-528, doi:10.1175/1520-0442(1991)004<0517: TPATPA $>2.0 . \mathrm{CO} ; 2$.

Li, Z. T., and M. Kafatos, 2000: Interannual variability of vegetation in the United States and its relation to El Niño/Southern Oscillation. Remote Sens. Environ., 71, 239-247, doi:10.1016/ S0034-4257(99)00034-6.

Loikith, P. C., and A. J. Broccoli, 2012: Characteristics of observed atmospheric circulation patterns associated with temperature extremes over North America. J. Climate, 25, 7266-7281, doi:10.1175/JCLI-D-11-00709.1.

, and - 2014: The influence of recurrent modes of climate variability on the occurrence of winter and summer extreme temperatures over North America. J. Climate, 27, 1600-1618, doi:10.1175/JCLI-D-13-00068.1.

Mantua, N. J., S. R. Hare, Y. Zhang, J. M. Wallace, and R. C. Francis, 1997: A Pacific interdecadal climate oscillation with impacts on salmon production. Bull. Amer. Meteor. Soc., 78, 1069-1079, doi:10.1175/1520-0477(1997)078<1069: APICOW $>2.0 . \mathrm{CO} ; 2$.

McAfee, S. A., and J. L. Russell, 2008: Northern annular mode impact on spring climate in the western United States. Geophys. Res. Lett., 35, L17701, doi:10.1029/2008GL034828.

McCabe, G. J., and M. D. Dettinger, 1999: Decadal variations in the strength of ENSO teleconnections with precipitation in the western United States. Int. J. Climatol., 19, 1399-1410, doi:10.1002/(SICI)1097-0088(19991115)19: $13<1399::$ AID-JOC457>3.0.CO;2-A.

, M. A. Palecki, and J. L. Betancourt, 2004: Pacific and Atlantic Ocean influences on multidecadal drought frequency in the 
United States. Proc. Natl. Acad. Sci. USA, 101, 4136-4141, doi:10.1073/pnas.0306738101.

Mesinger, F., and Coauthors, 2006: North American Regional Reanalysis. Bull. Amer. Meteor. Soc., 87, 343-360, doi:10.1175/ BAMS-87-3-343.

Mitchell, T. D., and P. D. Jones, 2005: An improved method of constructing a database of monthly climate observations and associated high-resolution grids. Int. J. Climatol., 25, 693-712, doi:10.1002/joc.1181.

Mo, K. C., and J. E. Schemm, 2008: Relationship between ENSO and drought over the southeastern United States. Geophys. Res. Lett., 35, L15701, doi:10.1029/2008GL034656.

Mote, P. W., A. F. Hamlet, M. P. Clark, and D. P. Lettenmaier, 2005: Declining mountain snowpack in western North America. Bull. Amer. Meteor. Soc., 86, 39-49, doi:10.1175/ BAMS-86-1-39.

Myoung, B., and Y. Deng, 2009: Interannual variability of the cyclone activity along the U.S. Pacific Coast: Influences on the characteristics of winter precipitation in the western U.S. J. Climate, 22, 5732-5747, doi:10.1175/2009JCLI2889.1.

— , and J. W. Nielsen-Gammon, 2010: The convective instability pathway to warm season drought in Texas. Part I: The role of convective inhibition and its modulation by soil moisture. J. Climate, 23, 4461-4473, doi:10.1175/2010JCLI2946.1.

Osborn, T. J., 2004: Simulating the winter North Atlantic Oscillation: The roles of internal and greenhouse gas forcing. Climate Dyn., 22, 605-623, doi:10.1007/s00382-004-0405-1.

Peings, Y., and G. Magnusdottir, 2014: Forcings of the wintertime atmospheric circulation by the multidecadal fluctuations of the North Atlantic Ocean. Environ. Res. Lett., 9, 034018, doi:10.1088/1748-9326/9/3/034018.

Porter, J. R., and M. A. Semenov, 2005: Crop responses to climatic variation. Philos. Trans. Roy. Soc. London, 360B, 2021-2035, doi:10.1098/rstb.2005.1752.

Portis, D. H., J. E. Walsh, M. El Hamly, and P. J. Lamb, 2001: Seasonality of the North Atlantic Oscillation. J. Climate, 14, 2069-2078, doi:10.1175/1520-0442(2001)014<2069: SOTNAO $>2.0 . \mathrm{CO} ; 2$.

Rivière, G., and I. Orlanski, 2007: Characteristics of the Atlantic storm-track eddy activity and its relation with the North Atlantic Oscillation. J. Atmos. Sci., 64, 241-266, doi:10.1175/ JAS3850.1.

Ropelewski, C. F., and M. S. Halpert, 1987: Global and regional scale precipitation patterns associated with the El Niño/ Southern Oscillation. Mon. Wea. Rev., 115, 1606-1626, doi:10.1175/1520-0493(1987)115<1606:GARSPP>2.0.CO;2.

— Southern Oscillation index. Mon. Wea. Rev., 115, 2161-2165, doi:10.1175/1520-0493(1987)115<2161:AEOTTS>2.0.CO;2.

Scaife, A. A., C. K. Folland, L. V. Alexander, A. Moberg, and J. R. Knight, 2008: European climate extremes and the North Atlantic Oscillation. J. Climate, 21, 72-83, doi:10.1175/ 2007JCLI1631.1.

Shukla, J., and J. M. Wallace, 1983: Numerical simulation of the atmospheric response to equatorial Pacific sea surface temperature anomalies. J. Atmos. Sci., 40, 1613-1630, doi:10.1175/ 1520-0469(1983)040<1613:NSOTAR >2.0.CO;2.
Stewart, I. T., D. R. Cayan, and M. D. Dettinger, 2005: Changes toward earlier streamflow timing across western North America. J. Climate, 18, 1136-1155, doi:10.1175/JCLI3321.1.

Straile, D., and N. C. Stenseth, 2007: The North Atlantic Oscillation and ecology: Links between historical time-series, and lessons regarding future climate warming. Climate Res., 34, 259-262, doi:10.3354/cr00702.

Sutton, R. T., and D. L. R. Hodson, 2005: Atlantic Ocean forcing of North American and European summer climate. Science, 309, 115-118, doi:10.1126/science.1109496.

Thompson, D. W. J., and J. M. Wallace, 1998: The Arctic Oscillation signature in the wintertime geopotential height and temperature fields. Geophys. Res. Lett., 25, 1297-1300, doi:10.1029/98GL00950.

,-- , and G. C. Hegerl, 2000: Annular modes in the extratropical circulation. Part II: Trends. J. Climate, 13, 1018-1036, doi:10.1175/1520-0442(2000)013<1018:AMITEC>2.0.CO;2.

Trenberth, K. E., 1990: Recent observed interdecadal climate changes in the Northern Hemisphere. Bull. Amer. Meteor. Soc., 71, 988-993, doi:10.1175/1520-0477(1990)071<0988: ROICCI $>2.0 . \mathrm{CO} ; 2$.

- 1997: The definition of El Niño. Bull. Amer. Meteor. Soc., 78, 2771-2777, doi:10.1175/1520-0477(1997)078<2771: TDOENO $>2.0 . \mathrm{CO} ; 2$.

— tions in the Pacific. Climate Dyn., 9, 303-319, doi:10.1007/ BF00204745.

Wang, H., R. Fu, A. Kumar, and W. Li, 2010: Intensification of summer rainfall variability in the southeastern United States during recent decades. J. Hydrometeor., 11, 1007-1018, doi:10.1175/2010JHM1229.1.

Wang, S.-Y., L. Hipps, R. R. Gillies, and J.-H. Yoon, 2014: Probable causes of the abnormal ridge accompanying the 20132014 California drought: ENSO precursor and anthropogenic warming footprint. Geophys. Res. Lett., 41, 3220-3226, doi:10.1002/2014GL059748.

Wanner, H., S. Brönnimann, C. Casty, D. Gyalistras, J. Luterbacher, C. Schmutz, D. B. Stephenson, and E. Xoplaki, 2001: North Atlantic Oscillation-Concepts and studies. Surv. Geophys., 22, 321-382, doi:10.1023/A:1014217317898.

Wettstein, J. J., and L. O. Mearns, 2002: The influence of the North Atlantic-Arctic Oscillation on mean, variance, and extremes of temperature in the northeastern United States and Canada. J. Climate, 15, 3586-3600, doi:10.1175/1520-0442(2002) 015<3586:TIOTNA > 2.0.CO;2.

Wolter, K., R. M. Dole, and C. A. Smith, 1999: Short-term climate extremes over the continental United States and ENSO. Part I: Seasonal temperatures. J. Climate, 12, 3255-3272, doi:10.1175/ 1520-0442(1999)012<3255:STCEOT>2.0.CO;2.

Woollings, T. J., B. J. Hoskins, M. Blackburn, and P. Berrisford, 2008: A new Rossby wave-breaking interpretation of the North Atlantic Oscillation. J. Atmos. Sci., 65, 609-626, doi:10.1175/2007JAS2347.1.

Zhang, Y., J. M. Wallace, and D. S. Battisti, 1997: ENSO-like interdecadal variability: 1900-93. J. Climate, 10, 1004-1020, doi:10.1175/1520-0442(1997)010<1004:ELIV>2.0.CO;2. 